\title{
Produção de mudas de batata doce em ambiente protegido com aplicação de extrato de Ascophyllum nodosum
}

\author{
Édina Regina Neumann; Juliano Tadeu V Resende; Letícia KP Camargo; Rafael R Chagas; Renato B Lima \\ Filho
}

Universidade Estadual do Centro-Oeste (UNICENTRO), Guarapuava-PR, Brasil; edynaneumann@gmail.com; jvresende@uol.com.br; leti_kpc@yahoo.com.br; rafaelr_chagas@hotmail.com; renatodelimafilho@hotmail.com

\section{RESUMO}

A batata doce é uma olerícola adaptada a climas tropicais e possui baixa tolerância a temperaturas amenas, o que reduz o tempo disponível para o cultivo na região Sul do Brasil. Portanto, técnicas que visem a otimização do processo, como a produção de mudas em bandejas em ambiente protegido, aliado à aplicação de bioestimulantes, torna-se uma alternativa eficiente para reduzir o ciclo da cultura. O objetivo do trabalho foi avaliar a influência do uso do extrato da alga Ascophyllum nodosum na produção de mudas de batata doce em bandejas em ambiente protegido. Utilizou-se o delineamento de blocos casualizados com parcela subdividida, com cinco concentrações do extrato de alga $(0,0 \% ; 0,5 \% ; 1,0 \% ; 1,5 \%$; e $2,0 \%)$ e três segmentos da rama da batata doce (basal, intermediária e apical), com 9 repetições. Foram avaliados aspectos de propagação vegetativa e massa fresca e seca dos órgãos da planta. Observaram-se resultados positivos para todas as características avaliadas, quando utilizado o segmento apical da rama, para a maioria das concentrações de extrato de alga aplicadas. Com relação às concentrações utilizadas, praticamente todas as características corresponderam ao incremento nas doses, independente do segmento da rama utilizado. Atribui-se à presença de citocininas e auxinas e outros componentes químicos presentes no extrato de $A$. nodosum e na própria estrutura da planta, os efeitos benéficos observados. Os melhores resultados foram encontrados no segmento apical combinado com a concentração de $1 \%$ do produto. $\mathrm{O}$ extrato de alga marinha otimizou a formação de mudas de batata doce em bandejas, contribuindo para o aumento de vigor e consequente precocidade das mesmas.

Palavras-chave: Ipomoea batatas, alga marinha, bioestimulante, reguladores vegetais.

\begin{abstract}
Production of sweet potato seedlings in protected environment with the application of Ascophyllum nodosum extract

The sweet potato is a crop adapted to tropical climates and has low tolerance to mild temperatures, which reduces the time available for cultivation in southern Brazil. Therefore, techniques aimed at process optimization, such as the production of seedlings in trays in protected environment, together with the application of biostimulants, becomes an efficient alternative to reduce the crop cycle. The objective was to evaluate the use of Ascophyllum nodosum seaweed extract in the production of sweet potato seedlings in trays under greenhouse conditions. We used the randomized block design with split plot with five extract concentrations $(0.0 \%, 0.5 \%, 1.0 \%$, $1.5 \%$ and $2.0 \%$ ) and three parts of the branch of sweet potato plants (basal, middle and apical) and 9 repetitions. We evaluated aspects of vegetative propagation and fresh and dry weight of the plant organs. Positive results were observed for all characteristics when used in the apical portion of the branch, regardless of the concentration of algae extract applied. With respect to the concentrations used, practically all the features corresponded to the increase in doses, regardless of the portion of the branch used. It is attributed to the presence of cytokinins and auxins and other chemicals present in the $A$.nodosum extract and in the structure of the plant, the beneficial effects observed. The best results were found on the apical portion, combined with the concentration of $1 \%$ of the product. The kelp extract optimized the formation of sweet potato seedlings in trays, contributing to the increase of force and consequent precocity of them.
\end{abstract}

Keywords: Ipomoea batatas, seaweed, bio-stimulant, plant growth regulators.

(Recebido para publicação em 2 de junho de 2016; aceito em 21 de abril de 2017) (Received on June 2, 2016; accepted on April 21, 2017)

\begin{abstract}
A batata doce (Ipomoea batatas) é originária das Américas Central e do Sul (Silva et al., 2004) e é utilizada na alimentação humana por meio do consumo de suas raízes e na produção de álcool (Camargo et al., 2013), sendo uma das hortaliças mais consumidas no Brasil (Barbosa, 2005). A parte
\end{abstract}

aérea pode ser utilizada na alimentação humana ou animal (Silva et al., 2004).

O Brasil destaca-se como principal produtor no continente latino americano, alcançando em 2011 uma produção de $544.820 \mathrm{t}$ em uma área de 43.879 ha, obtendo produtividade igual a $12,4 \mathrm{t} / \mathrm{ha}$. A região Sul é responsável pelo maior volume de produção, seguida da região Nordeste e Sudeste (IBGE, 2011).

A implantação da cultura ocorre por meio do uso de material propagativo, geralmente, obtido de ramas de lavouras comerciais (Rós \& Narita, 2011).

A cultura da batata doce expressa seu potencial vegetativo e consequen- 
temente produtivo, em locais ou épocas em que a temperatura média é superior a $24^{\circ} \mathrm{C}$ e tem seu crescimento retardado quando a temperatura é inferior a $10^{\circ} \mathrm{C}$ (Silva et al., 2004). Portanto, a condição climática é fator limitante ao cultivo dessa espécie, tendo em vista que a mesma não suporta geada. Assim, sua produção restringe-se aos períodos da primavera e verão, em regiões de clima subtropical, quando a temperatura elevada e a alta radiação solar favorecem o desenvolvimento da cultura, contando com apenas oito meses para a produção das ramas em viveiro e cultivo comercial.

Dessa maneira, técnicas que permitam a obtenção de número maior de mudas a partir de pequena quantidade de material vegetativo em tempo reduzido, devem ser utilizadas e otimizadas para se obter estruturas propagativas suficientes para a implantação da área de cultivo comercial o mais breve possível. Nesse sentido, a produção de mini estacas em bandejas de polipropileno em ambiente protegido seria a alternativa mais viável (Rós \& Narita, 2011).

A produção de mudas em bandejas permite ao produtor dedicar maior cuidado às plântulas, visto que a atividade é desenvolvida sob ambiente protegido, facilitando também, o controle de pragas e doenças, proporcionando elevada taxa de sobrevivência após o transplante e maior uniformidade das mudas a serem transplantadas ao campo, com destaque ainda para a redução do ciclo da cultura, resultando em precocidade.

Considerando o restrito período de cultivo em regiões de clima subtropical, a obtenção de maior precocidade na produção das mudas seria de grande importância. A utilização na agricultura de produtos que exibam ação bioestimulante (Castro, 2006) tem sido objeto de estudos de diversos autores (Zhang et al., 2002; Payan \& Stall, 2004). Produtos de origem natural, obtidos a partir do extrato da alga Ascophyllum nodosum têm sido utilizados como bioestimulantes em diversas culturas (Sangha et al., 2014), sendo utilizado na agricultura mundial por possuir em sua composição mais de 60 elementos químicos que propiciam para a planta diversos benefícios, entre eles, o desenvolvimento radicular, a melhoria dos processos de floração, o acúmulo de reservas na planta, a superação de processos de estresse, o fortalecimento da estrutura da planta, aperfeiçoa a eficiência dos insumos, aumenta a qualidade da planta, além de favorecer a vida microbiana no solo, inclusive na agricultura orgânica (Masny et al., 2004).

Especificamente, os extratos de Ascophyllum nodosum são constituídos por citocininas, auxinas, ácido abscísico, giberelinas, betaínas e alginatos (Tarakhovskay et al., 2007; Mackinnon et al., 2010) existindo ainda compostos não identificados que possuem atividade similar a de alguns hormônios vegetais e que também podem estimular sua produção nas plantas (Rayorath et al., 2008a,b).

Os mecanismos de ação do extrato de Ascophyllum nodosum ainda são pouco conhecidos e a sua elucidação é de extrema importância para a elaboração de estratégias que favoreçam o aumento da produtividade vegetal. $\mathrm{O}$ estudo de metodologias que favoreçam a fase de pegamento de mudas oriundas de estacas é de suma importância, já que nem sempre este método de propagação é bem-sucedido, sem contar que, para algumas espécies, é muito oneroso.

Assim, com a finalidade de otimização do processo de produção de mudas de batata doce, o presente trabalho teve como objetivo avaliar o crescimento e desenvolvimento de mudas de batata doce a partir de mini estacas provenientes de três segmentos da rama (basal, intermediário e apical) em bandejas de polipropileno em ambiente protegido com a aplicação de diferentes concentrações do extrato da alga marinha Ascophyllum nodosum.

\section{MATERIAL E MÉTODOS}

$\mathrm{O}$ experimento foi conduzido em casa de vegetação no Setor de Olericultura do Departamento de Agronomia da Universidade Estadual do Centro-Oeste (UNICENTRO), em Guarapuava-PR. A casa de vegetação foi mantida com fotoperíodo de $14 \mathrm{~h}$, temperatura em torno de $30 \pm 3^{\circ} \mathrm{C}$ e umidade relativa do ar em torno de $83 \pm 5 \%$.
Foram utilizadas estacas obtidas a partir de genótipos de batata doce, provenientes de regiões produtoras do município de Faxinal-PR (23⒌'59"S, $51^{\circ} 19^{\prime} 15^{\prime \prime} \mathrm{O}$, altitude $\left.824 \mathrm{~m}\right)$. As estacas foram preparadas com aproximadamente $15 \mathrm{~cm}$ ou com pelo menos quatro gemas de brotação, utilizando-se três segmentos diferentes da rama. Posteriormente, as estacas foram plantadas em bandejas de polipropileno de 50 células preenchidas com substrato comercial. Foram enterradas duas gemas, mantendo-se duas para fora do substrato. As bandejas foram dispostas em bancadas a 1,20 m de altura em casa de vegetação, irrigadas por microaspersão, com acionamento automático, em função da umidade relativa do ar.

O delineamento experimental utilizado foi em blocos casualizados em parcela subdividida no espaço, sendo considerada parcela, a concentração do extrato de alga e subparcela, o segmento da rama, em esquema fatorial 3 (segmento basal, intermediário e superior ou apical) x $5[0,0 \%$ (testemunha) $] ; 0,5 \%$; $1,0 \% ; 1,5 \%$ e $2,0 \%$ de extrato puro da alga marinha, Ascophyllum nodosum), com 9 repetições. O extrato puro da alga marinha, Ascophyllum nodosum utilizado foi o produto comercial Acadian ${ }^{\circledR}$. Além das diferentes concentrações utilizou-se uma testemunha apenas com água. Os tratamentos foram aplicados no substrato contido nas células das bandejas com auxílio de uma seringa, na quantidade de $15 \mathrm{~mL}$ do extrato diluído em água a cada 5 dias durante um período de 30 dias, totalizando 6 aplicações.

O produto Acadian ${ }^{\circledR}$ apresenta em sua composição 13,0 a 16,0\% de matéria orgânica, 1,01\% de aminoácidos (alanina, ácido aspártico e glutâmico, glicina, isoleucina, leucina, lisina, metionina, fenilalanina, prolina, tirosina, triptofano e valina), carboidratos e macro e micronutrientes como N, P, K, Ca, Mg, S, B, $\mathrm{Fe}, \mathrm{Mn}, \mathrm{Cu}$ e $\mathrm{Zn}$, além de hormônios vegetais como auxinas, giberelinas, citocininas e ácido abscísico, elicitores de resistência e auxiliares do transporte de micronutrientes.

$\mathrm{O}$ experimento foi implantado em 23/09/2011 e conduzido até 26/10/2011, quando as mudas apresentavam em tor- 
no de 15 a $20 \mathrm{~cm}$ de altura e com folhas expandidas, avaliando-se as seguintes características: massa fresca de raízes (determinação da massa em balança analítica do material após lavagem em água corrente e posterior secagem em temperatura ambiente até evaporação da umidade de toda parte radicular da muda, expresso em gramas); massa seca de raízes (pesagem em balança analítica do material seco em estufa de ventilação forçada de ar a $65^{\circ} \mathrm{C}$ por 72 horas, expresso em gramas); altura de planta (medida com auxílio de régua graduada desde o colo até o ápice da planta, expresso em $\mathrm{cm}$ ); massa fresca do caule e das folhas (pesagem em balança analítica de toda parte aérea da muda, expresso em gramas); massa seca do caule e das folhas (pesagem em balança analítica do material após secagem em estufa de ventilação forçada de ar a $65^{\circ} \mathrm{C}$, durante 72 horas, expresso em gramas); número de folhas e brotações por plantas (contagem do número total de folhas e brotações).

Os dados coletados foram submetidos à análise de variância e as médias comparadas pelo teste Tukey $(\mathrm{p} \leq 0,05)$ de probabilidade, utilizando o software Sisvar 4.0 (Ferreira, 2008). Os dados referentes às concentrações foram submetidos à análise de variância e regressão polinomial, sendo a significância do $\mathrm{R}^{2}$ das equações de regressão testadas pelo teste t. Os pontos de máximo e mínimo da equação da reta foram determinados por meio do cálculo do vértice da parábola.

\section{RESULTADOS E DISCUSSÃO}

Os principais fatores que interferem no crescimento e desenvolvimento das plantas são de natureza química. Os hormônios presentes nos extratos de algas são responsáveis pelos sinais químicos, carregam informações e modificam o estado fisiológico das células, dos tecidos e, em alguns casos de sistemas mais complexos (Sharma et al., 2012). Nesse contexto, uma mesma substância pode produzir respostas diferentes em diferentes fases do desenvolvimento da planta. Muitas vezes as respostas fisio- lógicas são consequências de alterações na relação entre diferentes hormônios vegetais, e não especificamente da ação individual de um deles.

A análise de variância da presente pesquisa demonstrou resultados significativos $(p \leq 0,01 ; p \leq 0,05)$ para a interação entre as fontes de variação (segmento $\mathrm{x}$ dose) para todas as características avaliadas.

Entre os segmentos avaliadas, o apical apresentou o melhor resultado para as características avaliadas, seguida do segmento intermediário para a maioria das doses de A. nodosum utilizadas (Tabela 1), demonstrando efeitos significativos no crescimento e desenvolvimento das plantas de batata doce em bandejas. O segmento basal das estruturas propagativas utilizadas demonstraram menor potencial de resposta à ação da alga, independente da concentração utilizada.

Normalmente tecidos mais jovens apresentam melhor resposta aos efeitos estimulantes dos biorreguladores, pois se encontram em plena atividade metabólica com células mais bem supridas de componentes químicos, principalmente de carboidratos. À medida que os tecidos vão envelhecendo, ocorre redução dos efeitos dos reguladores, muito em decorrência da degradação de proteínas receptoras do estímulo e da idade do tecido (Davies, 2004, Sharma et al., 2012).

O rendimento energético das células é medido pelo saldo entre a respiração (carboidrato consumido) e a fotossíntese (carboidrato produzido). Esta relação é afetada por fatores abióticos e bióticos, com destaque para idade do tecido, temperatura, umidade e mesmo concentração de reguladores de crescimento. Tecidos mais jovens apresentam o metabolismo mais acelerado, produzem mais clorofila, apresentam mais cloroplastos e mitocôndrias, estruturas básicas para geração de energia metabolizável, utilizada no processo de divisão celular e diferenciação (Taiz \& Zeiger, 2008). Portanto, naturalmente, os tecidos mais jovens, no caso, o segmento apical, serão sempre mais eficientes no balanço energético, permitindo maiores ganhos para a planta (Carvalho et al., 2013). A massa fresca de raízes foi influenciada pelas doses aplicadas em todos segmentos de ramas analisadas, ocorrendo incremento no crescimento e desenvolvimento (Figura 1A).

Segundo relatado por Gontijo et al. (2003), tão importante quanto a concentração dos reguladores de crescimento na indução da rizogênese adventícia é a existência de um adequado balanço hormonal endógeno, especialmente entre auxinas, giberelinas e citocininas, ou seja, um equilíbrio entre promotores e inibidores do processo de iniciação radicular (Ramachandra \& Ravishankar, 2002). Em tecidos mais jovens o equilíbrio entre os reguladores é mais evidente, o que explica os resultados superiores obtidos nas estacas do segmento apical da rama de batata doce quanto ao acumulo de massa fresca nas raízes. Estes autores mencionam ainda que a maneira mais comum de promover esse equilíbrio é pela aplicação exógena de reguladores de crescimento sintéticos.

Todas as equações apresentaram ajuste quadrático, sendo que no segmento basal o valor máximo obtido foi 1,26 g na concentração de $0,95 \%$, o segmento intermediário apresentou um máximo de $2,26 \mathrm{~g}$ na concentração de $0,66 \%$ e o segmento apical apresentou um máximo de 2,93 g na concentração de $1,25 \%$. Esse incremento é promovido, presumivelmente, pelas citocininas que podem atuar na superação de dormência, que em conjunto com as auxinas são responsáveis pelo estímulo da divisão celular, promovendo antecipação e aceleração na formação de raízes (Taiz \& Zeiger, 2008).

O aumento do volume radicular propicia maior ganho na absorção de água e nutrientes, resultando em maior desenvolvimento da planta e consequentemente maior eficiência metabólica. Contudo, observou-se na presente pesquisa que concentrações mais elevadas do extrato de algas, inibiram o crescimento do sistema radicular da batata doce, caracterizando o ajuste quadrático da equação. Ao considerar o extrato rico em reguladores de crescimento, em específico as auxinas (Mackinnon et al., 2010; Khan et al., 2012), ressalta-se que o referido regulador quando em desequilíbrio com a citocinina, reduz o crescimento dos tecidos radiculares, explicando, assim, os resultados obtidos 
no presente estudo.

Silva et al. (2012) observaram que o comprimento do sistema radicular em couve manteiga aumentou $7 \%$ ao aplicar $4 \mathrm{~mL} / \mathrm{L}$ do extrato de alga, quando comparado com a testemunha $(0 \mathrm{~mL} / \mathrm{L})$; a utilização de $6 \mathrm{~mL} / \mathrm{L}$ promoveu uma redução de $15 \%$ nesta variável, quando comparado ao valor médio da concentração utilizada imediatamente inferior.
A massa seca de raízes apresentou ajuste quadrático com predomínio crescente de acordo com o aumento das concentrações (Figura 1B), para o segmento apical, sendo que na concentração

Tabela 1. Características avaliadas em cada segmento de batata doce nas diferentes concentrações de Ascophyllum nodosum (characteristics evaluated in each segment of sweet potato at different concentrations of Ascophyllum nodosum). Guarapuava, UNICENTRO, 2011.

\begin{tabular}{|c|c|c|c|c|c|}
\hline Segmento & $0,5 \%$ & $1,0 \%$ & $1,5 \%$ & $2,0 \%$ & $2,5 \%$ \\
\hline & \multicolumn{5}{|c|}{ Massa fresca aérea (g) } \\
\hline Basal & $1,39 a$ & $2,50 \mathrm{a}$ & $0,99 b$ & $2,17 \mathrm{~b}$ & $1,47 b$ \\
\hline Intermediário & $2,13 a$ & $2,57 \mathrm{a}$ & $2,81 \mathrm{a}$ & $3,29 b$ & $3,56 \mathrm{a}$ \\
\hline \multirow[t]{2}{*}{ Apical } & $2,62 \mathrm{a}$ & $2,13 \mathrm{a}$ & $3,25 \mathrm{a}$ & $4,69 \mathrm{a}$ & $2,91 \mathrm{a}$ \\
\hline & \multicolumn{5}{|c|}{ Massa fresca do caule (g) } \\
\hline Basal & $1,19 b$ & $1,87 \mathrm{a}$ & $0,88 \mathrm{c}$ & $1,27 b$ & $1,14 b$ \\
\hline Intermediário & $2,01 \mathrm{a}$ & $1,91 \mathrm{a}$ & $1,95 b$ & $2,15 \mathrm{a}$ & $2,29 \mathrm{a}$ \\
\hline \multirow[t]{2}{*}{ Apical } & $2,25 \mathrm{a}$ & $1,87 \mathrm{a}$ & $2,97 \mathrm{a}$ & $2,83 \mathrm{a}$ & $2,47 \mathrm{a}$ \\
\hline & \multicolumn{5}{|c|}{ Massa fresca de raiz (g) } \\
\hline Basal & $1,10 \mathrm{~b}$ & $1,92 \mathrm{a}$ & $0,75 b$ & $1,17 b$ & $1,06 \mathrm{~b}$ \\
\hline Intermediário & $2,21 \mathrm{a}$ & $2,37 \mathrm{a}$ & $2,18 \mathrm{a}$ & $2,22 \mathrm{a}$ & $2,65 \mathrm{a}$ \\
\hline \multirow[t]{2}{*}{ Apical } & $2,33 \mathrm{a}$ & $2,34 \mathrm{a}$ & $2,90 \mathrm{a}$ & $3,01 \mathrm{a}$ & $2,09 \mathrm{a}$ \\
\hline & \multicolumn{5}{|c|}{ Massa seca aérea (g) } \\
\hline Basal & $0,17 \mathrm{~b}$ & $0,34 \mathrm{a}$ & $0,12 b$ & $0,27 b$ & $0,27 b$ \\
\hline Intermediário & $0,30 \mathrm{ab}$ & $0,36 \mathrm{a}$ & $0,37 \mathrm{a}$ & $0,43 b$ & $0,48 \mathrm{a}$ \\
\hline \multirow[t]{2}{*}{ Apical } & $0,45 \mathrm{a}$ & $0,33 \mathrm{a}$ & $0,47 \mathrm{a}$ & $0,64 \mathrm{a}$ & $0,42 \mathrm{a}$ \\
\hline & \multicolumn{5}{|c|}{ Massa seca do caule (g) } \\
\hline Basal & $0,28 b$ & $0,44 \mathrm{a}$ & $0,20 \mathrm{~b}$ & $0,34 b$ & $0,30 \mathrm{~b}$ \\
\hline Intermediário & $0,49 \mathrm{ab}$ & $0,46 \mathrm{a}$ & $0,41 b$ & $0,51 \mathrm{ab}$ & $0,54 \mathrm{a}$ \\
\hline \multirow[t]{2}{*}{ Apical } & $0,57 \mathrm{a}$ & $0,44 \mathrm{a}$ & $0,68 \mathrm{a}$ & $0,64 \mathrm{a}$ & $0,58 \mathrm{a}$ \\
\hline & \multicolumn{5}{|c|}{ Massa seca de raiz (g) } \\
\hline Basal & $0,07 \mathrm{~b}$ & $0,08 \mathrm{~b}$ & $0,05 b$ & $0,03 b$ & $0,04 \mathrm{~b}$ \\
\hline Intermediário & $0,13 \mathrm{ab}$ & $0,14 \mathrm{ab}$ & $0,11 \mathrm{ab}$ & $0,06 b$ & $0,22 \mathrm{a}$ \\
\hline \multirow[t]{2}{*}{ Apical } & $0,18 \mathrm{a}$ & $0,17 \mathrm{a}$ & $0,17 \mathrm{a}$ & $0,17 \mathrm{a}$ & $0,12 b$ \\
\hline & \multicolumn{5}{|c|}{ Altura de planta $(\mathrm{cm})$} \\
\hline Basal & $3,11 \mathrm{~b}$ & $7,44 \mathrm{~b}$ & $5,44 b$ & $7,78 b$ & $3,22 b$ \\
\hline Intermediário & $6,00 \mathrm{~b}$ & $8,78 \mathrm{ab}$ & $8,22 b$ & $10,22 \mathrm{ab}$ & $10,89 a$ \\
\hline \multirow[t]{2}{*}{ Apical } & $10,11 \mathrm{a}$ & $10,78 \mathrm{a}$ & $12,67 \mathrm{a}$ & $13,00 \mathrm{a}$ & $10,89 \mathrm{a}$ \\
\hline & \multicolumn{5}{|c|}{ Número de folhas } \\
\hline Basal & $4,00 \mathrm{~b}$ & $8,67 \mathrm{a}$ & $2,89 b$ & $6,22 \mathrm{a}$ & $3,22 b$ \\
\hline Intermediário & $6,33 \mathrm{ab}$ & $7,22 \mathrm{ab}$ & $7,67 \mathrm{a}$ & $8,00 \mathrm{a}$ & $8,33 \mathrm{a}$ \\
\hline \multirow[t]{2}{*}{ Apical } & $6,78 \mathrm{a}$ & $5,22 \mathrm{~b}$ & $7,00 \mathrm{a}$ & $7,44 a$ & $5,78 \mathrm{ab}$ \\
\hline & \multicolumn{5}{|c|}{ Número de brotações } \\
\hline Basal & $2,67 b$ & $4,22 \mathrm{a}$ & $2,11 b$ & $3,22 b$ & $2,78 \mathrm{a}$ \\
\hline Intermediário & $4,11 \mathrm{ab}$ & $4,33 \mathrm{a}$ & $4,22 \mathrm{a}$ & $3,78 \mathrm{ab}$ & $4,22 \mathrm{a}$ \\
\hline Apical & $5,11 \mathrm{a}$ & $3,67 \mathrm{a}$ & $4,44 a$ & $5,11 \mathrm{a}$ & $3,56 a$ \\
\hline
\end{tabular}

Médias na coluna, seguidas pela mesma letra, não diferem entre si, pelo teste de Tukey, a 5\% de probabilidade (averages in the column, followed by same letters do not differ, Tukey test at $5 \%$ probability). 
mais elevada (2,0\%), obteve-se um acúmulo de 0,22 g. Nos segmentos basal e intermediário, não houve resposta para as doses do extrato aplicadas, não diferindo estatisticamente da testemunha, dose zero. O aumento na massa seca de raízes de estacas do segmento apical das ramas de batata doce é atribuído ao maior volume fresco de raízes encontrado, sendo o mesmo estimulado pelas concentrações crescentes de extrato de alga, no segmento apical, conforme mencionado acima.

Tecidos jovens apresentam maior atividade metabólica e consequentemente melhor balanço energético, com maior produção e redistribuição de fotoassimilados, permitindo maior saldo de carboidratos na relação fotossíntese/ respiração. Os segmentos basal e intermediário, não responderam ao extrato de alga aplicado, assim presume-se menor saldo de massa seca, tendo em vista que tecidos mais lignificados são menos eficientes na produção e redistribuição de fotoassimilados, sendo o balanço energético prejudicado em função do maior dispêndio de energia para realização das funções de transporte e respiração.

Plântulas de Vigna radiata foram incrementadas pela aplicação de extratos das algas Sargassum plagiophyllum, Turbinaria conoides, Padina tetrastromatica, Dictyota dichotoma e Caulerpascal pelliformis nas sementes, sendo observados acréscimos no comprimento da raiz principal e da parte aérea, assim como no número de raízes laterais e massa fresca e seca das plântulas em até $105 \%, 106 \%, 123 \%$, 93\% e $85 \%$, respectivamente (Kavipriya et al., 2011).

Quanto à altura da planta houve incremento em todos os segmentos, no entanto, nos segmentos basal e apical os efeitos positivos não foram observados nas concentrações mais elevadas (Figura 1C). Doses mais altas do extrato de alga proporcionaram menor crescimento da parte aérea das estacas de batata doce para os segmentos basal e apical.

De acordo com Davies (2004), a concentração de reguladores, especialmente as auxinas e giberelinas ocorre de forma diferenciada ao longo do caule da planta. As auxinas se concentram mais nas gemas apicais, enquanto as giberelinas, estão presentes em maiores concentrações no segmento basal da estrutura de propagação. Portanto, esse comportamento da altura da parte aérea das estacas em função dos segmentos utilizados, pode ser explicado em função do efeito dos componentes químicos dos biorreguladores, principalmente entre auxinas e giberelinas, tanto de origem endógena quanto exógena no processo de desenvolvimento e crescimento da planta.

Estes atuam sinergicamente para regular a divisão celular e de forma antagônica para controlar a formação de gemas e raízes laterais, sugerindo múltiplos mecanismos de interação (Cato, 2006). Para efetivo crescimento deve haver um balanço ideal entre citocinina e auxina. Nesse sentido acredita-se que a condição fisiológica e hormonal de ambas as estruturas, aliada às concentrações aplicadas não foram suficientes para estabelecer este equilíbrio, que por sua vez condicionou o comportamento observado.

O segmento basal teve ajuste quadrático, onde se observou valor máximo de 8,14 cm com uma concentração aproximada de $1,01 \%$. O segmento intermediário apresentou comportamento linear crescente e na maior concentração utilizada no trabalho $(2 \%)$ a altura atingiu $10,58 \mathrm{~cm}$. O segmento apical apresentou comportamento quadrático, na qual se observou valor máximo de $12,50 \mathrm{~cm}$ com uma concentração aproximada de 1,17\%. Segundo Oliveira et al. (2011), o incremento na altura da planta pode ser atribuído ao efeito da alga marinha Ascophyllum nodosum, considerando que a mesma possui em sua composição citocinina, que promove a divisão celular e a auxina que promove o alongamento das células, influenciando diretamente na altura da planta.

As citocininas são sintetizadas na extremidade das raízes e transportadas de modo ascendente pelo xilema até a parte aérea, juntamente com água e sais minerais absorvidos pelo sistema radicular. Estes compostos exercem papel importante na regulação fonte-dreno, afetando a partição de fotoassimilados, por controlarem o crescimento e outros processos de desenvolvimento (Taiz \& Zeiger, 2008).
A massa fresca do caule das mudas de batata doce (Figura 1D) nos segmentos basal e apical apresentou comportamento quadrático, sendo que o valor máximo no segmento basal foi de $1,52 \mathrm{~g}$ na concentração de aproximadamente $0,86 \%$ de extrato de alga e no segmento apical foi de $2,87 \mathrm{~g}$ na concentração de aproximadamente $1,14 \%$, enquanto o segmento intermediário apresentou comportamento linear crescente com 2,29 g na maior concentração utilizada $(2 \%)$.

Normalmente a distribuição dos reguladores entre as partes da planta é diferenciada, principalmente em função da idade dos tecidos, portanto, presume-se que esse comportamento possa ser em decorrência da concentração do bioestimulante nessas regiões, conforme mencionado acima. Nos tecidos mais jovens há uma predominância das auxinas, visto ser o local de síntese da mesma. Nos tecidos basais há maior acúmulo de giberelinas e menor de auxinas. Acredita-se que no segmento intermediário ocorra uma distribuição mais equilibrada, justificando assim os resultados obtidos para a característica altura de plantas e massa fresca de caule.

$\mathrm{O}$ aumento da massa fresca possivelmente foi influenciado pelas giberelinas, pois as mesmas participam do crescimento do caule, tendo entre suas principais funções a capacidade de reverter o nanismo e a capacidade de substituir o estímulo do fotoperíodo (Roters, 2007).

Quanto à massa seca do caule, todos os segmentos avaliados apresentaram ajuste quadrático para a equação, sendo que os segmentos basal e apical seguiram a mesma tendência observada para altura de plantas e massa fresca de caule. Por outro lado, no segmento intermediário, o aumento da concentração aplicada, proporcionou maior acumulo de massa seca no caule $(0,54 \mathrm{~g})$, na maior concentração aplicada (2\%) (Figura 1E). No segmento basal o valor máximo obtido foi de $0,40 \mathrm{~g}$ na concentração de $0,95 \%$. No segmento apical o valor máximo encontrado foi de $0,66 \mathrm{~g}$ na concentração de $1,06 \%$.

$\mathrm{O}$ estímulo na divisão celular causado pelas citocininas e o alongamento das células influenciado pelas auxinas, 


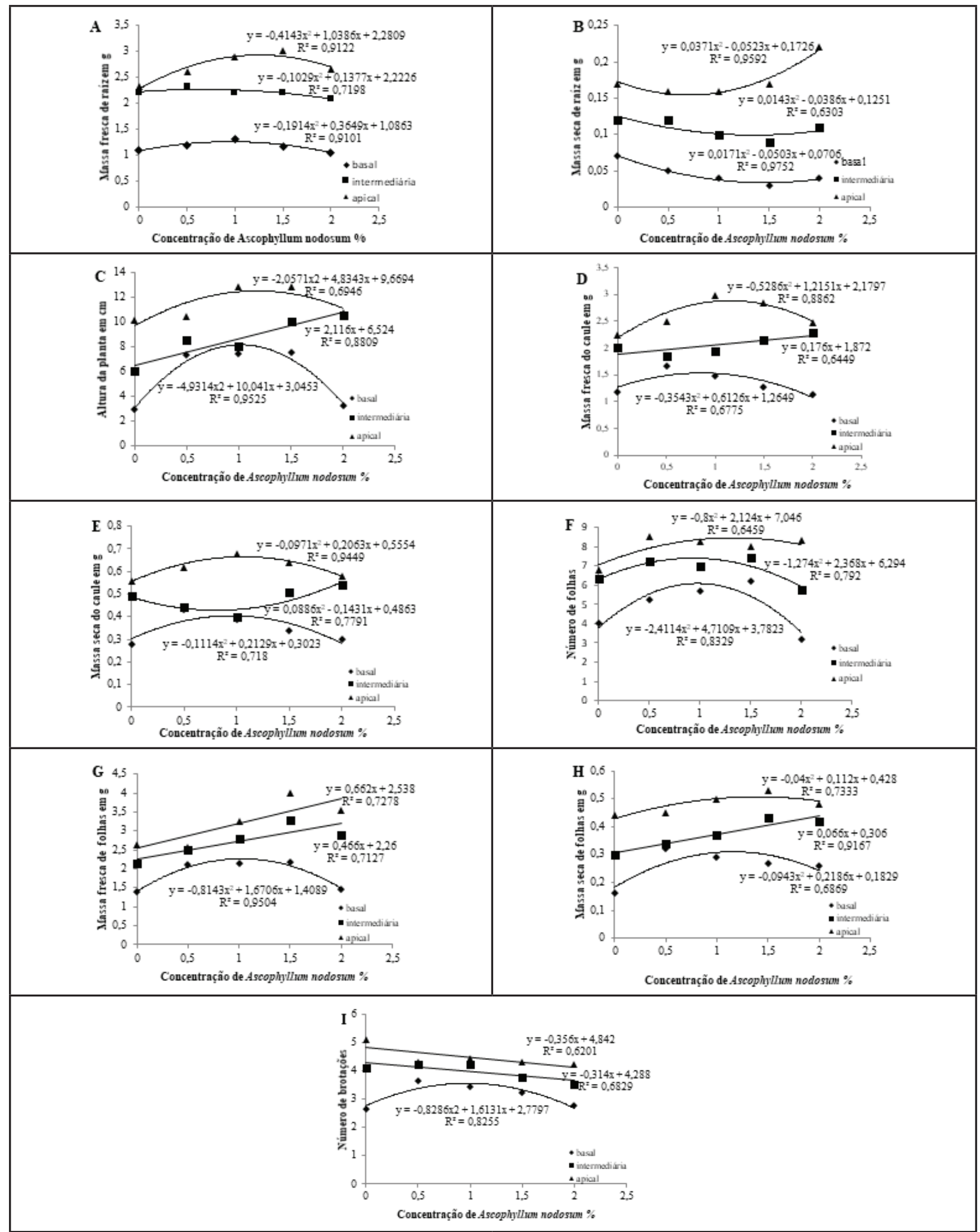

Figura 1. A) massa fresca de raízes (g); B) massa seca de raízes (g); C) altura da planta (cm); D) massa fresca do caule (g); E) massa seca do caule (g); F) número de folhas; G) massa fresca de folhas $(\mathrm{g}) ; \mathrm{H})$ massa seca de folhas (g); I) número de brotações de plantas de batata doce submetidas a diferentes doses de extrato de alga (Ascophyllum nodosum) $\{$ A) fresh mass of roots ( $\mathrm{g}$ ); B) dry mass of roots (g); C) plant height (cm); D) fresh mass of stalk (g); E) dry mass of stalk (g); F) number of leaves; G) fresh mass of leaves g); H) dry mass of leaves (g); I) number of sprouts of sweet potato plants submitted to different doses of sea weed extract (Ascophyllum nodosum) $\}$. Significativo a $5 \%$ de probabilidade pelo teste de Tukey (significant at 5\%, Tukey test). Guarapuava, UNICENTRO, 2011. 
atuam diretamente na altura da planta e, consequentemente, na massa fresca e seca do caule. Os resultados encontrados estão de acordo com aqueles obtidos por Oliveira et al. (2011) na produção de mudas de maracujazeiro aplicadas com extrato de alga onde pode-se observar incremento positivo significativo com relação à altura de planta e número de folhas.

Em trabalho realizado com mudas de pinheiro (Pinus pinea), a aplicação foliar do extrato de alga promoveu o crescimento da parte aérea com aumento do comprimento e de massa alocada neste segmento (Atzmon \& Van Staden, 1994).

O número de folhas influencia diretamente no desenvolvimento da planta, pois proporciona aumento expressivo na área fotossintética da mesma (Roters, 2007). No presente trabalho o número de folhas foi influenciado significativamente em decorrência do segmento da rama utilizado e da concentração aplicada. Porém, com o aumento da concentração em níveis mais elevados, observou-se decréscimo no número de folhas (Figura 1F), provavelmente, devido a um desequilíbrio hormonal entre citocininas e auxinas provenientes do extrato de algas.

Todos os segmentos apresentaram ajuste quadrático para o número de folhas, sendo que o segmento basal apresentou valor máximo de 6,2 folhas com uma concentração de $0,97 \%$; o segmento intermediário apresentou valor máximo de 7,6 folhas na concentração de $0,92 \%$ e o segmento apical apresentou valor máximo de 8,7 folhas na concentração de 1,33\%. A diferenciação das gemas caulinares é diretamente dependente do estímulo hormonal que recebe e também do estádio fenológico da planta, podendo originar folhas ou mesmo flores (Taiz \& Zeiger, 2008).

Em experimento realizado em Mossoró com couve (Brassica oleracea $\mathrm{cv}$. Couve-Manteiga da Georgia), observou-se que a aplicação do extrato de Ascophyllum nodosum na dose de 3,8 $\mathrm{mL} / \mathrm{L}$ teve efeito benéfico no desenvolvimento inicial e, posteriormente, na produtividade das plantas que apresentaram um aumento do número de folhas e da massa seca da parte aérea (Silva et al., 2012).

Em outro estudo na região Nordeste do Brasil, foi demonstrado que a aplicação do extrato de Ascophyllum nodosum (Natural WSP) na dose $75 \mathrm{~g} / 100 \mathrm{~L}$ do extrato de algas pulverizado sobre as folhas e $750 \mathrm{~g} /$ ha sobre o solo, influenciou positivamente a produtividade de alface (Lactuca sativa cv. Elba) (Pinto et al., 2005).

Também houve acréscimo no número de folhas $(16,6 \%)$ e massa fresca $(24,3 \%)$ e seca $(24,6 \%)$ da parte aérea de alface crespa 'Vera' tratada com extratos de algas marinhas do gênero Sargassum e Laminaria, na dosagem recomendada de $2 \mathrm{~L} /$ ha aplicada via foliar aos $14 \mathrm{e}$ aos 21 dias do transplante (Cecato \& Moreira, 2013).

Na massa fresca das folhas houve incremento significativo em todos os segmentos com o aumento das concentrações de extrato de alga, sendo que apenas no segmento basal observou-se ajuste quadrático para a equação, com decréscimo após a concentração de 1,02\% do extrato aplicado (Figura 1G). No segmento basal, o valor máximo observado foi de 2,26 g para a concentração supracitada. Os segmentos intermediário e apical apresentaram ajuste linear crescente com valor de 2,9 e 3,56 g respectivamente, na maior concentração utilizada ( $2 \%)$.

Na massa seca de folhas observou-se incremento em todos os segmentos da rama de batata doce utilizada (Figura $1 \mathrm{H})$. Os segmentos basal e apical apresentaram ajuste quadrático, sendo que no segmento basal o valor máximo observado foi de $0,30 \mathrm{~g}$ de massa seca na concentração de $1,15 \%$ do extrato e, a apical, o valor máximo observado foi de $0,50 \mathrm{~g}$ de massa seca de folha a 1,4\%. $\mathrm{O}$ segmento intermediário apresentou ajuste linear crescente, atingindo o valor de $0,42 \mathrm{~g}$ na maior concentração utilizada $(2 \%)$.

As massas, fresca e seca de folhas, são diretamente influenciadas pelo aumento no número de folhas e da área foliar das mesmas, tanto pelo acúmulo de substâncias, quanto pelo rendimento fotossintético para produção de carboidratos. As citocininas influenciam o movimento de nutrientes para a folha a partir de outras partes da planta, assim como promovem o desenvolvimento de cloroplastos, aumentando a fotossíntese e, consequentemente, a síntese de compostos ricos em energia (Taiz \& Zeiger, 2008).

O número de brotações foi inversamente proporcional ao aumento das concentrações de extrato de alga aplicado (Figura 1I). O segmento apical e o segmento intermediário apresentaram comportamento linear decrescente à medida que se aumentou a concentração do extrato da alga. O segmento basal apresentou ajuste quadrático para a equação, sendo o valor máximo de 3,56 brotações na concentração de $0,97 \%$ do extrato de alga. Normalmente, tecidos jovens apresentam atividade metabólica superior aos tecidos mais lignificados, com maior desenvolvimento e produção de substâncias químicas, entre elas hormônios, bem como melhor resposta a estímulos exógenos. Com o surgimento das primeiras brotações, ocorre elevada síntese de auxinas que conduzem à chamada dominância apical, que é caracterizada pela brotação mais vigorosa das gemas terminais das estacas, inibindo, portanto a ação das citocininas nas gemas adventícias, diminuindo consideravelmente o número de brotações laterais na estaca. Nesse sentido, acredita-se que o incremento na concentração não contribuiu para aumentar as brotações, tendo em vista que as proteínas receptoras da sinalização são mais efetivas nas gemas apicais, que originaram as folhas em detrimento às gemas laterais que originariam as brotações.

Para a cultivar Da Chang Kao de Crataegus pinnatifida houve reduções do número de brotações (27,27$50,00 \%$ ) quando aplicado extrato de $A$. nodosum em estacas, estando portanto de acordo com os resultados obtidos no presente trabalho. No entanto, para Prunus marianna cv. GF 8-1, o número de brotações aumentou (225,0-587,5\%), quando comparado ao controle. Em Prunus mahaleb cv. Bogdány, dependendo do produto utilizado, o número de brotações foi reduzido $(19,23 \%)$ ou elevado $(23,07 \%)$ (Carvalho \& Castro, 2014). Deste modo, nota-se que os efeitos dos extratos de alga são dependentes não só da espécie, 
mas também das cultivares.

Os efeitos promovidos pelas citocininas incluem a inibição ou estímulo de diversos processos fisiológicos e bioquímicos nos vegetais. Em associação às auxinas e em função da razão auxina/ citocinina, as citocininas estão envolvidas no processo de crescimento e diferenciação. Uma relação alta de auxina/ citocinina promove o desenvolvimento do sistema radicular, em contrapartida, a baixa relação entre esses dois hormônios vegetais propicia o desenvolvimento da parte aérea (Taiz \& Zeiger, 2008). Uma maior concentração da auxina em relação à citocinina e o consequente desbalanço nessa razão pode explicar o decréscimo das brotações com o aumento da concentração.

Correlações significativas foram obtidas entre a maioria das características avaliadas para os segmentos basal, apical e intermediário, sendo algumas negativas e outras positivas, conforme as características. Esses resultados demonstram o efeito da alga nos parâmetros biométricos da planta, como altura, número de folhas e brotações, promovendo maior crescimento e desenvolvimento. $\mathrm{O}$ extrato de alga Ascophyllum nodosum promove um desenvolvimento mais rápido das raízes adventícias, estabelecendo, portanto, o desenvolvimento efetivo da muda. A relação entre o aumento da massa fresca e seca das folhas deve-se ao estímulo da divisão celular promovido pela citocinina, proporcionando o acréscimo no número de células, promovendo a expansão das mesmas.

No segmento apical praticamente todas as características apresentaram correlações significativas quando contrastadas entre si, com comportamento semelhante ao do segmento intermediário. O número de folhas apresentou correlação negativa e altamente significativa com o número de brotações. A massa fresca de folha se correlacionou de forma significativa com a massa seca de folhas. O comportamento observado ocorreu, provavelmente, devido à presença de tecidos mais jovens no segmento apical, ainda não totalmente diferenciados e menos lignificados, o que permite uma resposta rápida aos estímulos causados pelo tratamento com o extrato da alga. A presença de tecidos mais jovens também influencia na emissão de raízes adventícias, tendo o seu desenvolvimento acelerado em função de nutrientes essenciais, bem como do equilíbrio nutricional propiciado pelo tratamento com o extrato de alga.

Por meio dos resultados obtidos pode-se perceber influência positiva da aplicação do extrato de Ascophyllum nodosum na produção de mudas de batata doce. Considerando as condições climáticas do local no qual o experimento foi desenvolvido (Guarapuava-PR), onde o espaço de tempo disponível para a implantação da cultura é reduzido, é relevante dispor de mudas mais vigorosas e com um sistema radicular previamente desenvolvido, para que assim, sofram menor estresse com o transplante e possam se adaptar melhor às condições de campo, bem como tenham maior precocidade.

Recomenda-se utilizar para a produção de mudas de batata doce, o segmento apical da rama, combinada com uma concentração de 1,0 a 1,5\% de extrato de Ascophyllum nodosum, pois proporcionam melhores resultados quando considerados os aspectos de propagação e massa fresca e seca dos órgãos da planta.

\section{REFERÊNCIAS}

ATZMON, N; VAN STADENJ. 1994.The effect of seaweed concentration on the growth of Pinuspineaseedlings.New Forest 8: 279-288.

BARBOSA, AHD. 2005.Rendimento de batatadoce com adubação orgânica.Areia-PB: $\mathrm{UFPb}, 79 \mathrm{p}$ (Dissertação mestrado).

CAMARGO, LKP; MÓGOR, AF; RESENDE, JTV; SILVA, PR. 2013. Establishment and molecular characterization of a sweet potato germplasm bank of the highlands of Parana State, Brazil. Genetics and Molecular Research 12: 5574-5588.

CARVALHO, MEA; CASTRO, PRC; NOVEMBRE, ADLC; CHAMMA, HMCP. 2013. Seaweed extract improves the vigor and provides the rapid emergence of dry bean seeds. American-EurasianJournalofAgricult uralandEnviromental Science 13: 1104-1107.

CARVAlHO, MEA; CASTRO, PRC. 2014. Extratos de algas e suas aplicações na agricultura. Série Produtor Rural 56, 58p.
CASTRO, PRC. 2006. Agroquímicos de controle hormonal na agricultura tropical. Série Produtor Rural 32, 46p.

CATO, SC. 2006. Ação de bioestimulante nas culturas do amendoinzeiro, sorgo $e$ trigo e interações hormonais entre auxinas, citocininas e giberilinas. Piracicaba: USPESALQ. 74p (Tese doutorado).

CECATO, A; MOREIRA, GC. 2013. Aplicação de extratos de algas em alface. Cultivando o Saber 6: 89-96.

DAVIES, PJ. 2004. Plant hormones: biosynthesis, signal transduction, action. Dordrecht:Kluwer Academic Publishers, 750p.

FERREIRA, DF. 2008. SISVAR: um programa para análises e ensino de estatística. Revista Symposium 6:36-41.

GONTIJO, AMMC; BARRETO, RE; SPEIT, G; REYES, VAV; VOLPATO, GL; SALVADORI, DMF. 2003. Anesthesia of fish with bezocaine does not interfere with comet assay results. MutationResearch 534: 165-172.

IBGE. 2013. Produção agrícola municipal. Culturas temporárias e permanentes 2011. Disponível em:<http://www.ibge.gov. $\mathrm{br} /$ home/estatistica/pesquisas/pesquisa_ resultados.php?id_pesquisa $=44>$. Acesso em: 1 de nov. de 2015.

KAVIPRIYA, R; DHANALAKSHMI, PK; JAYASHREE, S; THANGARAJU, N. 2011. Seaweed extract as a bioestimulant for legume crop, green gram. Journal of Ecobiotechnology 8: 16-19.

KHAN, AS; AHMAD, B; JASKANI MJ; AHMAD, R; MALIK, AU. 2012. Foliar application of mixture of amino acids and seaweed (Ascophyllum nodosum) extract improve growth and physicochemical properties of grapes. International Journal of Agriculture and Biology 14: 383-388.

MACKINNON, SL; HILTZ, D; UGARTE, R; CRAFT, CA. 2010.Improved methods of analysis for betaines in Ascophyllum nodosum and its commercial seaweed extracts.Journal of Applied Phycology 22: 489-494.

MASNY, A; BASAK, A; ZURAWICZ, E. 2004. Effects of foliar applications of Kelpak SL and Goëmar BM 86 preparations on yield and fruit quality in two strawberry cultivars. JournalofFruitand Ornamental PlantResearch 12: 23-27.

OLIVEIRA, LAA; GOÉS, GB; MELO, IGC; COSTA, ME; SILVA, RM. 2011. Uso do extrato de algas (Ascophyllum nodosum) na produção de mudas de maracujazeiroamarelo. Revista Verde de Agroecologia e Desenvolvimento Sustentável6: 01-04.

PAYAN, JPM; STALL, W. 2004. Effects of aminolevoluric acid and acetyl thioproline on weed free and weed infested St. Augustine Turfgrass. Florida StateHorticulturalSociety117: 282-285.

PINTO, PAC; MENDOZA, EBC; PINTO, ACC; ARAGAO, CA; DOURADO, FWN; LIMA NETO, IS. 2005. Eficiência agronômica 
de extrato de algas Ascophyllum nodosum (Natural WSP) aplicado na cultura da alface (Lactuca sativa L.). In: CONGRESSO DA SOCIEDADE BRASILEIRA DE CIÊNCIA DO SOLO, 30.Anais...Recife: SBCS.

RAMACHANDRA, RAO; RAVISHANKAR, GA. 2002. Plant cell cultures: chemical factories of secondary metabolites. Biotechnology Advances 20: 101-153.

RAYORATH, P; JITHESH, MN; FARID, A;
KHAN, W; PALANISAMY, R; HANKINS, SD; CRITCHLEY, AT; PRITHIVIRAJ, B. 2008a. Extracts of the brown seaweed Ascophyllum nodosum induce gibberelic acid $\left(\mathrm{GA}_{3}\right)$ - independent amylase activity in barley. Journal função do uso de extrato de alga (Ascophyllum nodosum). Revista Verdede Agroecologia e Desenvolvimento Sustentável6: 7-11.

TAIZ, L; ZEIGER, E. 2008. Fisiologia vegetal. 4.ed. Porto Alegre. 772p.

TARAKHOVSKAY, ER; MASLOV, YI; SHISHOVA, MF. 2007. Phytohormones in algae.Russian Journal of Plant Physiology 54: $163-170$

ZHANG, X; SCHMIDT, RE; ERVIN, HE; DOAK, S. 2002. Creeping bentgrass physiology responses to natural plant growth regulators and iron under two regimes. Hortscience 37: 898-902. 